\title{
REVIEW
}

NOVEMBER/ DECEMBER 1996

Michael J. Dueker is a senior economist at the Federal Reserve Bank of St. Louis. Apostolos Serletis is a professor of economics at the University of Calgary. Nick Meggos provided research assistance.

\section{The Sensitivity of Empirical Studies to Alternative Measures of the Monetary Base and Reserves}

\section{Michael J. Dueker and Apostolos Serletis}

\footnotetext{
he adjusted monetary base has long been an index measure that aggregates the effects of Federal Reserve openmarket operations, discount window lending and reserve-requirement changes. Traditionally the adjustment procedure has assumed that a change in required reserves leads to a one-to-one change in the demand for reserves. Recently, however, Anderson and Rasche (1996) have revised the St. Louis measure of the adjusted monetary base to reflect that many depository institutions are not bound by reserve requirements, so their demand for reserves does not change with further reductions in reserve requirements. Using bank-level data, Anderson and Rasche determine for each financial institution whether it is bound at the time of the change in required reserves, and they adjust the reserves only of bound banks.

A second innovation of Anderson and Rasche is to include banks' required clearing balances in the measure of bank reserves. In terms of helping to reduce the likelihood of payments-related overdrafts in banks' accounts with the Fed, clearing balances are functionally equivalent to the reserve account deposits that are formally pledged towards satisfying reserve require-
}

ments. Furthermore, many nonbound banks freely choose to hold deposits at the Fed under clearing balance agreements.

Hence Anderson and Rasche's revisions affect both components of traditional measures of adjusted reserves: the source base (through the addition of required clearing balances) and the reserve adjustment magnitude (through more sophisticated analysis of how changes in reserve requirements affect the demand for reserves). Anderson and Rasche's article contains a full description of the revisions they make to adjusted reserves in the post1980 period.

Because the adjusted monetary base and adjusted reserves have seen wide empirical use as indicators of monetary policy, it is important to know whether the Anderson and Rasche revisions alter existing empirical evidence regarding the stance and potency of monetary policy. The present paper applies both the old and revised measures in empirical models to examine whether the revisions cause the conclusions to change. Any altered empirical results would be a consequence of the data revision, but not a rationale or justification for the revision. One would expect that the growth rates of the revised and the old measures of the adjusted monetary base would differ most greatly in periods surrounding reserve requirement changes and periods when required clearing balances change rapidly. Just as it is necessary to examine whether the switch from fixed-weight to chain-type measures of GDP alters our understanding of business cycles and recent economic events, similar tests of monetary policy indicators should accompany revisions to the adjusted monetary base.

The first section of this article presents McCallum and Hargraves' (1995) monetary impulse measure for the revised and old base measures. In a similar vein, we use McCallum's (1987, 1988) monetary base rule as a model of U.S. monetary 


\section{Figure 1}

\section{Reserves Growth}

Percent Change over Previous Year

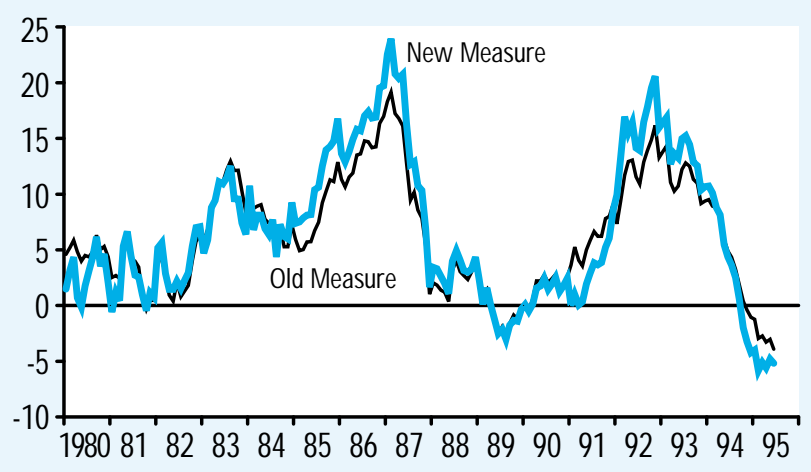

policy and estimate the coefficients and nominal GDP targets that best describe the growth in both the revised and old adjusted base measures. The second section compares Vector Autoregressions (VARs) that use either the revised or old measures of the base and reserves, starting with the model from Sims (1992) and Bernanke and Blinder (1992) that views innovations in the federal funds rate as monetary policy shocks. We also examine VARs proposed by Eichenbaum (1992); Christiano, Eichenbaum and Evans (1995); and Strongin (1995), all of which view innovations in non-borrowed reserves as a monetary policy shock. The section concludes with a VAR from Bernanke and Mihov (1995) that is tailored to take into account changes in the Federal Reserve's operating procedures when identifying monetary policy shocks.

The third section looks at the new and old measures of the monetary base and reserves in the context of a structural VAR, following the "monetarist" specification of Haslag and Hein (1995). The question posed here is whether open-market operations and reserve requirement changes have differential effects on the economy. As another example, we repeat the Loungani and Rush (1995) "credit-view" regressions that test for significant effects from reserve-requirement shocks on output and investment.
Empirical models that focus on variables corresponding to reserve-requirement shocks, such as Loungani and Rush, best highlight the differences between the two base series. Reserve-requirement shocks do not have a significant impact on output when the old base and reserves measures are used, but they do exert a significant influence when the revised measures are applied. In the estimated McCallum rule, we find differences in the velocity forecast errors between the old and revised bases, especially after 1985 . In the post-1985 period, the revised base measure leads to a lower estimated target nominal GDP growth than the old base. In the VARs, the results are qualitatively the same for both the revised and old bases, although there are minor differences in the variance decompositions. The variance decompositions from a structural VAR of Haslag and Hein (1995) also yield the interesting result that the old definitions imply a relatively large role for source-base shocks in explaining inflation. The revised data, on the other hand, attribute inflation variability less to source-base shocks and more to shocks to the inflation rate itself.

The revised St. Louis adjusted monetary base and reserves series have been chained back to 1959.1 The VARs in section II use this full 1960-1995 sample. Several other empirical investigations used shorter sample periods as noted in the text. As Anderson and Rasche (1996) explain, the old and revised measures differ most significantly in the post-1980 period, because required clearing bal ances came into existence in 1980 and grew in popularity, and the percentage of nonbound banks grew appreciably. To see the differences, it helps to focus on reserves, because the currency component of the base is identical for both measures, and 90 percent of the base consists of currency. Figure 1 illustrates year-over-year growth rates of the old and revised measures of adjusted St. Louis reserves. The revised series shows faster growth from 1985 to 1988, perhaps presaging the build-up of inflation that peaked in 1990. The revised measure also experienced slower growth 
than the old measure in 1991 prior to a sluggish recovery.

\section{THE MONETARY BASE IN MONETARY POLICY INDICATORS}

\section{McCallum and Hargrave's Monetary Impulse Measure}

In a recent study for the International Monetary Fund, McCallum and Hargraves (1995) present a comparison of the "monetary impulses" generated across time by central banks in the G-7 countries. They sum monetary base growth, adjusted for changes in reserve requirements, and a medium-term forecast of velocity growth. With this measure of monetary stimulus, McCallum and Hargraves examine whether current monetary policy actions (summarized by growth in the adjusted monetary base) suggest higher or lower inflationary potential, relative to current inflation. Hence their monetary impulse measure serves as a natural vehicle for the joint study of differences in growth rates between the two adjusted base measures and the differences in their predicted velocities. A given sustained level of monetary impulse ought to translate eventually into nominal spending growth of equal magnitude, due to the velocity adjustment:

$$
\Delta \mathrm{y}_{\mathrm{tt}-1}=\Delta \mathrm{m}_{\mathrm{t}}+\Delta[\mathrm{y}-\mathrm{m}]_{\mathrm{tt}-1},
$$

where $y$ is nominal spending and $m$ is the monetary base (both in logs). Subscript $t \mid t-1$ indicates a forecast based on information available through the previous period. The velocity forecasts in our calculated monetary impulse measures are from a conditionally heteroscedastic time-varying coefficient model estimated via the Kalman filter, using quarterly data from 1960. The first three years of data were reserved for an initial estimate of the coefficients. The explanatory variables in the model are lagged velocity, lagged M 1 growth, and the lagged first difference of the three-month Treasury bill rate. Further details on the velocity forecasting method are in Dueker (1993).

\section{Figure 2 \\ Monetary Impulse Measures for the United States}

Percent Change from Previous Year

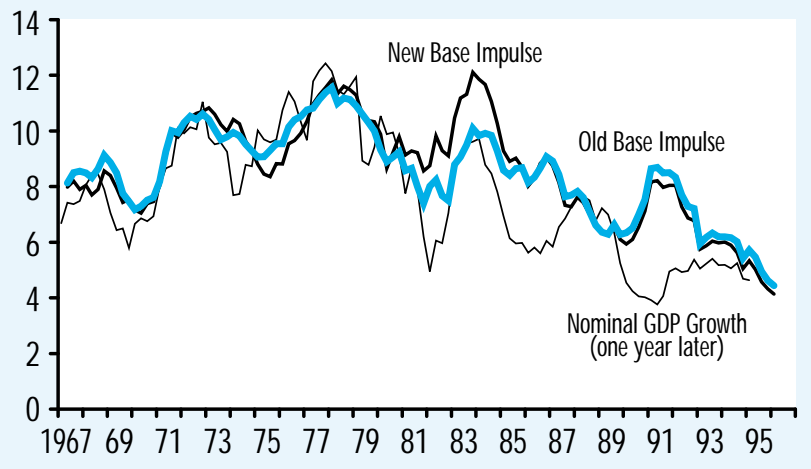

For a visual test of the predictive power of the monetary impulse measures, Figure 2 plots two-year moving averages of the monetary impulse measures with nominal GDP growth in the following year. ${ }^{2}$ Both monetary impulse measures overpredicted the surge in nominal GDP growth between 1983 and 1985, because they underpredicted the fall in velocity that followed the disinflation of the early 1980s. The revised adjusted base yielded a monetary impulse measure that predicted the magnitude of the increase in nominal GDP growth from 1983 to 1985 but overstated the level. The monetary impulse measure from the old base, on the other hand, underpredicted nominal GDP's acceleration but overstated the level by less. Since 1985, both monetary impulse measures have generally overpredicted future nominal GDP growth, primarily because of two slowdowns in nominal GDP growth: one in 1986 and another corresponding with the 1990-91 recession. For the past six years, however, the monetary impulse measure from the revised base has remained consistently below that from the old base by about 0.5 percent, on average.

\section{McCallum's Rule as an Estimated Equation}

Another empirical exercise similar in spirit to the monetary impulse measure described above consists of estimating an econometric model in which the central
${ }^{2}$ In the chart, the point plotted as the monetary impulse in 199001, for example, is the two-year moving average covering 1988Q1 to 1990Q1. At that same date, the "lead" of nominal GDP growth is a twoyear moving average covering 198901 to 199101. 


\section{REVIEW}

N OVEMBER/ DECEMBER 1996

\section{Figure 3}

\section{Forecast Error Variances for Velocities of Adjusted Base Measures}

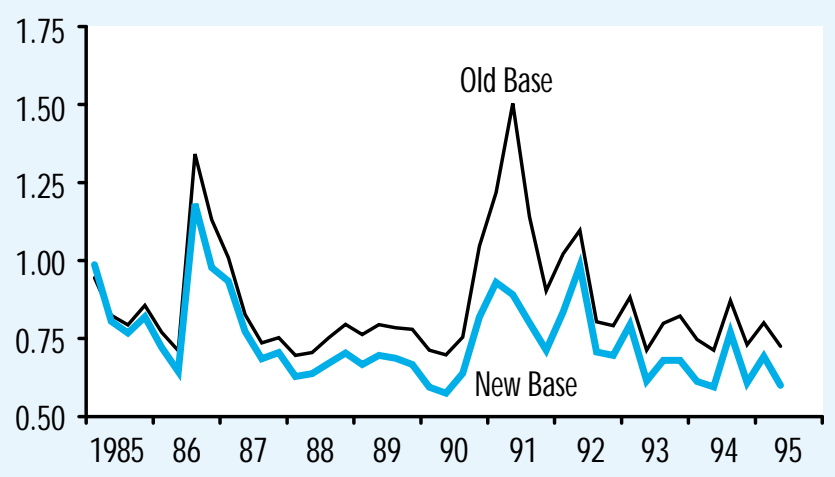

\section{Figure 4}

\section{Nominal GDP Growth Targets from Two Base Measures}

Percent Change over Previous Year

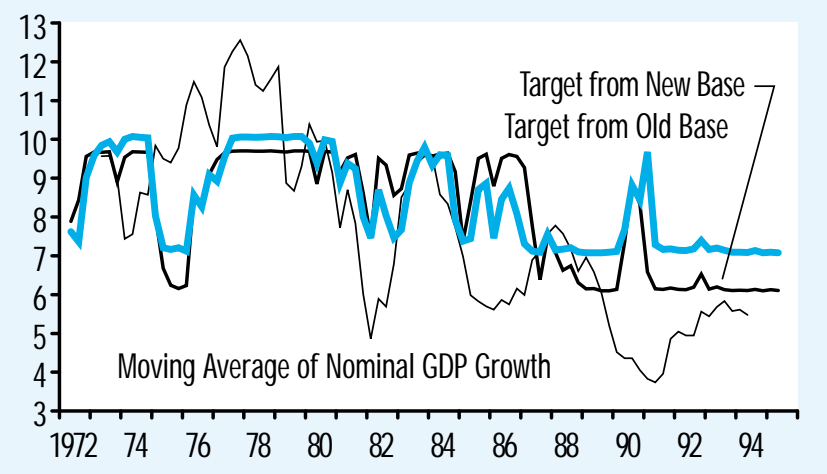

bank's willingness to let the monetary base grow at its historical rate elucidates its implicit nominal GDP growth targets. In this section we present another method of deriving base-implied nominal GDP growth rates, and we compare results for both base measures. The starting point is McCallum's rule, which sets quarterly base growth according to a target growth rate for nominal GDP, a forecast of base velocity growth, and a feedback parameter on the gap between the actual and target levels of nominal GDP:

$$
\Delta \mathrm{m}_{\mathrm{t}}=\lambda_{0 \mathrm{t}}-\Delta[\mathrm{y}-\mathrm{m}]_{\mathrm{tt}-1}+\lambda_{1 \mathrm{t}}(\hat{\mathrm{y}}-\mathrm{y})_{\mathrm{t}-1} .
$$

The parameter $\lambda_{0 t}$ is the (possibly time-varying) target rate of nominal GDP growth. The log of the monetary base is $m, y$ is log nominal GDP, and $(y-m)$ is the log of base velocity. Finally, $\hat{y}$ is the target value of $y$. The forecast of base velocity indicates how fast money ought to grow in order to hit the nominal GDP growth target. Simulations of McCallum's rule require a fully-specified stochastic model of how nominal GDP growth will respond to the rule-implied base growth.

As an alternative to simulations, Dueker and Fischer (1996) use McCallumtype rules as models of policy and estimate the parameters that best describe observed base growth as an outcome of nominal GDP targeting. We conduct the estimation exercise twice, once for the revised (new) measure of the adjusted monetary base and once for the old measure, and look for differences in the path of the inferred target rates for nominal GDP growth. If the two measures are nearly perfect substitutes, then the inferred target rates of nominal GDP growth ought not differ appreciably. As described earlier, the model used to generate one-step-ahead forecasts is a time-varying parameter model with heteroscedastic errors. Estimates of the forecast error variances for the growth rates of the velocities of the old and revised adjusted base measures differ across time, especially after 1985 . Figure 3 , which focuses on the post-1985 period, shows that the forecast error variance for the velocity of the old measure of the adjusted base is about 15 percent greater than the corresponding variance for the revised measure of the adjusted base.

Inserting the velocity forecasts into Equation 1 and adding a mean-zero error term that has time-varying variance $\sigma_{\mathrm{t}}^{2}$, we arrive at an econometric model of nominal GDP targeting. We also drop from Equation 1 the feedback from the level of nominal GDP, because all estimations found the feedback parameter $\lambda_{1}$ to be near zero:

$$
\Delta \mathrm{m}_{\mathrm{t}}=\lambda_{0 \mathrm{t}}-\Delta[\mathrm{y}-\mathrm{m}]_{\mathrm{tt}-\mathrm{I}}+\mathrm{e}_{\mathrm{t}}
$$

Because the implicit nominal GDP growth target of the Federal Reserve has 
likely changed over the past 20 years, we allow $\lambda_{0}$ to vary over time according to an unobservable, two-state Markov process. Thus, the estimation problem includes uncovering estimates of the probabilities that the GDP will be in high and low nominal growth target states in different time periods. The inferred value of the implicit growth target will be the probabilityweighted sum of the high-growth and low-growth parameters. For notation we use $\lambda_{0}(S 1)$ to convey that $\lambda_{0}$ is a parameter tied to state variable $S 1$, where $S 1$ is a binary variable representing the nominal growth targets; similarly, notation for the variance $\sigma^{2}(\mathrm{~S} 2)$ indicates that $\sigma^{2}$ changes with another state variable S2. To allow for the possibility that interest-rate changes have fatter-tailed distributions than the normal distribution, we allow e to have a student-t distribution. Subject to these Markov-switching state variables, Equation 2 becomes Equation 3.

(3) $\Delta m_{t}=\lambda_{0}(S 1)-\Delta[y-m]_{t \mid t-1}+e_{t}$, where $e_{t} \sim$ student-t (mean $\left.=0, n, \sigma^{2}(S 2)\right)$, Variance $(e)=\sigma^{2}(S 2) n /(n-2)$, and $\mathrm{S} 1 \in\{0,1\} \quad S 2 \in\{0,1\}$.

The two Markov processes are assumed to undergo transitions between their states independently from one another for reasons of tractability. In this case, the transition probabilities can be summarized as

$$
\begin{aligned}
& \operatorname{Prob} .\left(S 1_{\mathrm{t}}=0 \mid S 1_{\mathrm{t}-1}=0\right)=\mathrm{p}_{1}, \\
& \operatorname{Prob} .\left(S 1_{\mathrm{t}}=1 \mid S 1_{\mathrm{t}-1}=1\right)=\mathrm{q}_{1}, \\
& \operatorname{Prob} .\left(S 2_{\mathrm{t}}=0 \mid S 2_{\mathrm{t}-1}=0\right)=\mathrm{p}_{2} \text {, and } \\
& \operatorname{Prob} .\left(S 2_{\mathrm{t}}=1 \mid S 2_{\mathrm{t}-1}=1\right)=\mathrm{q}_{2} .
\end{aligned}
$$

Note that without the independence assumption for S1 and S2, we would have to estimate sixteen transition probabilities instead of four.

\section{Estimation Results for}

\section{U.S. Data 1973-1995}

Using data from the past 23 years

(1973-95), we obtain two sets of

\begin{tabular}{|c|c|c|}
\hline Parameter & Revised Measure & Old Measure \\
\hline$\lambda_{0}(S 1=0)$ & $9.71(.325)$ & $10.9(.365)$ \\
\hline$\lambda_{0}(S 1=1)$ & $6.09(.336)$ & $7.06(.346)$ \\
\hline$\sigma^{2}(\Omega 2=0)$ & $1.60(.043)$ & $.116(.035)$ \\
\hline$\sigma^{2}(52=1)$ & $.606(.211)$ & $.623(.235)$ \\
\hline$p_{1}$ & $.960(.034)$ & $.914(.068)$ \\
\hline$q_{1}$ & $.950(.042)$ & $.943(.046)$ \\
\hline$p_{2}$ & $.947(.048)$ & $.958(.033)$ \\
\hline$q_{2}$ & $.888(.083)$ & $.903(.073)$ \\
\hline $1 / n$ & $6 \mathrm{E}-04$ & $9 \mathrm{E}-05(1.5 \mathrm{E}-04)$ \\
\hline Log-Likelihood & -84.98 & -76.29 \\
\hline No. of parameters & 9 & 9 \\
\hline
\end{tabular}
parameter estimates, one from each

\section{Table 1}

\section{Indicator Model of Base Growth}

Note: Standard errors are in parentheses.

measure of the adjusted base. Table 1 contains the parameter estimates. The most important difference between the two sets of parameters is in the estimated low nominal GDP growth target: $\lambda_{0}(S 1=1)=7.07$ when the old adjusted monetary base is the presumed policy instrument and $\lambda_{0}(S 1=1)$ $=6.09$ when the new adjusted monetary base is used. Figure 4 (opposite page) plots the model-implied target or baseline rate of nominal GDP growth, where the inferred target is equal to the probability-weighted sum of $\lambda_{0}(S 1=0)$ and $\lambda_{0}(S 1=1)$. The estimated target or baseline growth rates are plotted with a two-year centered moving average of actual nominal GDP growth. Figure 4 shows that the 6.0 percent nominal GDP growth target inferred from the new adjusted monetary base better matches the actual trend in nominal GDP growth since 1988 , relative to the 7.0 percent trend inferred from the old adjusted monetary base. This finding concurs with the differences from Figure 2 between the 
two corresponding monetary impulse measures, in which the implied nominal GDP growth rate is lower from approximately 1989 on, when the revised measure of the monetary base is used.

\section{IS THE ESTIMATED ROLE OF MONETARY POLICY IN VARS ROBUST TO DIFFERENT MEASURES OF THE ADJ USTED BASE AND RESERVES?}

In this section, we consider both nonstructural and structural VAR specifications applied to data from 1960 to the present. In nonstructural VARs, the ordering of the variables matters for the inferences. Hence, when analyzing the effects of monetary policy shocks, the econometrician must decide for the entire sample whether interest rates are set before the money supply is determined (an interest-rate targeting operating procedure) or the money supply is exogenously set before interest rates are determined (a monetary targeting operating

3 Because the VARs are run in levels and the coefficients have non-standard unit-root distributions, the marginal significance levels reported in the tables are not exact. Nevertheless, they are still useful for relative comparisons between specifications employing the new and old base measures.

${ }^{4}$ Since the St. Louis adjusted reserves series has always been spliced across a break in 1980, it is not technically correct to subtract nominal borrowings from adjusted reserves to arive at a measure of nonborrowed reserves. All previous studies that use St. Louis adjusted reserves to calculate nonborrowed reserves have used the simple difference, however, and ours is no exception, given that no Reserve Adjustment Magnitude (RAM) exists that is tailored specifically to nonborrowed reserves. procedure). We begin with a comparison of nonstructural VARs in which the interest rate is assumed to be determined before the money supply. The comparison of interest is to run the revised and old monetary measures through otherwise indentical models. We conclude the section with a structural VAR that is designed to identify monetary policy shocks in a framework that allows for changes in operating procedures between interest-rate and monetary targeting within the sample period.

\section{Four Variable VAR Models with Fed Funds Rate Policy Shocks}

We look at Sims' classic four-variable (interest rates, money, the price level and output) VAR. We use monthly data in levels. ${ }^{3}$ The federal funds rate, $F F$, is the interest rate and is assumed to be determined before the money supply, as suggested by Sims $(1980,1992)$ and Bernanke and Blinder (1992). The price level is measured by the log of the consumer

\section{Table 2}

VAR RESULTS: FOUR-VARIABLE SYSTEMS WITH THE WOLD ORDERING \{FF, $M, P, Y\}$

Marginal Significance Levels for Exclusion of Lags

\begin{tabular}{|c|c|c|c|c|}
\hline Equation & FF & $M$ & $\mathbf{P}$ & $Y$ \\
\hline \multicolumn{5}{|l|}{ OLDMB } \\
\hline OLDMB & .000 & .000 & .491 & .011 \\
\hline P & .000 & .007 & .000 & .255 \\
\hline Y & .091 & .007 & .094 & .000 \\
\hline \multicolumn{5}{|l|}{ NEWMB } \\
\hline $\mathrm{FF}$ & .000 & .839 & .130 & .003 \\
\hline NEWMB & .000 & .000 & .326 & .000 \\
\hline p & .000 & .008 & .000 & .166 \\
\hline Y & .000 & .004 & .053 & .000 \\
\hline \multicolumn{5}{|l|}{ OLDTR } \\
\hline $\mathrm{FF}$ & .000 & .855 & .112 & .000 \\
\hline OLDTR & .000 & .000 & .024 & .005 \\
\hline p & .000 & .026 & .000 & .675 \\
\hline Y & .125 & .035 & .238 & .000 \\
\hline \multicolumn{5}{|l|}{ NEWTR } \\
\hline $\mathrm{FF}$ & .000 & .790 & .140 & .003 \\
\hline NEWTR & .000 & .000 & .014 & .001 \\
\hline P & .000 & .023 & .000 & .488 \\
\hline Y & .020 & .044 & .180 & .000 \\
\hline \multicolumn{5}{|l|}{ OLDNBRD } \\
\hline & .000 & .550 & .161 & .002 \\
\hline OLDNBRD & .003 & .000 & .026 & .037 \\
\hline P & .000 & .010 & .000 & .326 \\
\hline Y & .510 & .176 & .427 & .000 \\
\hline \multicolumn{5}{|l|}{ NEWNBRD } \\
\hline & .000 & .720 & .151 & .003 \\
\hline NEWNBRD & .001 & .000 & .034 & .062 \\
\hline p & .000 & .000 & .000 & .245 \\
\hline Y & .147 & .408 & .449 & .000 \\
\hline
\end{tabular}

NOTES: Sample period, monthly data: 1959:1 - 1996:6. The models have been estimated with 13 monthly lags using the Sims (1992) and Bernanke and Blinder (1992) \{FF, M, P, Y $\}$ ordering. Low values imply strong marginal predictive power. Variance decompositions are for a five-year horizon.

price index, P, money by various variables, and output by the log of the industrial production index, $Y$. Among the monetary variables, MB stands for the monetary base, TR for total reserves, and NBRD for nonborrowed reserves. The order of the variables in the VAR is $\{F F, M B, P, Y\}$. For the lag length, we follow Sims (1987) and set it equal to one year plus one period; the extra month is added because it can sometimes capture seasonal effects not 
removed by seasonal adjustment of the data.

Table 2 reports the marginal significance levels of Granger causality F-tests for six different measures of money: old and revised monetary base; old and revised total reserves; old and revised non-borrowed reserves. In particular, p-values are for the null hypothesis that lags of a particular right-hand-side variable (indicated in the column heading) can be excluded from one of the system's equations (indicated in the row heading). The variance decompositions show percentages of the fiveyear forecast-error variance of a variable explained by its own shocks versus shocks to the other variables.

The marginal significance levels in Table 2 indicate that lags of the fed funds rate do not significantly influence industrial production in the systems where money is measured by the old monetary base or total reserves, but they do have a significant impact in the system with the new monetary base and new total reserves. In the system with nonborrowed reserves, lags of the funds rate do not significantly affect output when either measure is used. ${ }^{4}$ Thus, the evidence regarding whether monetary policy shocks significantly affect output varies according to the measure of money that is used. One possible explanation for the contradictory conclusions reached about the predictive power of fed funds rate shocks across the different measures of money is that Granger causality tests are sensitive to the nonorthogonality between the right-hand-side variables (see, for example, Bernanke and Blinder, 1992, for a discussion of this issue). In this regard, it should be noted that the fed funds rate correlates more with the base and total reserves than with nonborrowed reserves:

$$
\begin{gathered}
\rho\left(\mathrm{FF}_{\mathrm{t}}, \mathrm{OLDNBRD}_{\mathrm{t}}\right)=.282 \text { and } \\
\rho\left(\mathrm{FF}_{\mathrm{t}}, \mathrm{NEWNBRD_{ \textrm {t } }}\right)=.248 .
\end{gathered}
$$

The forecast error variance decompositions in Table 3 show that innovations in money (independently of how it is measured) explain a very small percentage of
Table 3

VAR RESULTS: FOUR-VARIABLE SYSTEMS

\begin{tabular}{|c|c|c|c|c|}
\hline \multicolumn{5}{|c|}{ recast Error Variance Decompositions (60-Month Horizon) } \\
\hline Equation & FF & M & $\mathbf{P}$ & $Y$ \\
\hline \multicolumn{5}{|l|}{ OLDMB } \\
\hline $\mathrm{FF}$ & 49.947 & 1.366 & 16.367 & 32.318 \\
\hline OLDMB & 62.058 & 35.216 & 0.069 & 2.655 \\
\hline $\mathrm{p}$ & 8.327 & 1.930 & 72.761 & 16.981 \\
\hline \multirow{2}{*}{\multicolumn{5}{|c|}{ NEWM B }} \\
\hline & & & & \\
\hline $\mathrm{FF}$ & 49.518 & 3.046 & 19.843 & 27.592 \\
\hline NEWMB & 54.139 & 37.076 & 2.080 & 6.703 \\
\hline p & 10.629 & 1.720 & 72.393 & 15.255 \\
\hline y & 56.539 & 0.556 & 6.549 & 36.355 \\
\hline \multicolumn{5}{|l|}{ OLDTR } \\
\hline $\mathrm{FF}$ & 45.634 & 2.134 & 10.839 & 41.391 \\
\hline OLDTR & 60.444 & 28.465 & 3.196 & 7.896 \\
\hline P & 4.608 & 3.088 & 66.331 & 25.971 \\
\hline y & 39.888 & 6.984 & 6.075 & 47.051 \\
\hline \multicolumn{5}{|l|}{ NEWTR } \\
\hline $\mathrm{FF}$ & 38.009 & 8.895 & 17.483 & 35.611 \\
\hline NEWTR & 34.235 & 36.913 & 26.888 & 1.962 \\
\hline $\mathrm{p}$ & 4.506 & 1.729 & 70.959 & 22.804 \\
\hline Y & 36.519 & 9.137 & 7.920 & 46.421 \\
\hline \multicolumn{5}{|l|}{ OLDNBRD } \\
\hline FF & 45.186 & 2.284 & 8.159 & 44.369 \\
\hline OLDNBRD & 59.438 & 30.656 & 0.821 & 9.082 \\
\hline $\mathrm{P}$ & 4.209 & 0.730 & 62.210 & 32.849 \\
\hline Y & 31.155 & 2.754 & 12.827 & 53.262 \\
\hline \multicolumn{5}{|l|}{ NEWNBRD } \\
\hline $\mathrm{FF}$ & 36.202 & 8.672 & 12.462 & 42.662 \\
\hline NEWNBRD & 32.935 & 43.716 & 14.916 & 8.431 \\
\hline $\mathrm{p}$ & 3.456 & 1.438 & 65.846 & 29.258 \\
\hline Y & 28.662 & 4.382 & 13.312 & 53.643 \\
\hline
\end{tabular}
WITH THE WOLD ORDERING \{FF, M, P, Y\}

the variance of output. In contrast, innovations in the fed funds rate explain a very high percentage of the variance of industrial production, especially when money is measured by the base, about 56 percent in the case of NEW MB. Replacing NEW MB with NEWTR, however, reduces this statistic to 37 percent and to 29 percent when NEW NBRD is used. Moreover, in the variance decompositions of Table 3 , the new measures of money perform generally the same as the corresponding old ones.

Solid lines in Figures 5-7 (following pages) show the impulse response func- 
tions of each of the four variables (interest rate, money, prices, and output) to each of the six measures of money. Responses (based on orthogonalized innovations with the ordering as shown in the charts) are plotted over a horizon of five years. Dashed lines denote one standard deviation band, computed according to the Monte Carlo method described in Doan (1992, Example 10.1) with 500 draws from the posterior distribution of the VAR coefficients and the covariance matrix of the innovations. ${ }^{5}$

In general, the qualitative responses pictured in Figures 5-7 do not differ substantially between the old and revised money series. Minor differences are that, in Figure 5, the response of output to a shock in the old base measure is persistently positive, whereas the revised base measure predicts negative effects of a monetary shock on output at long horizons. However, the responses are not significantly different from zero in either case. In Figure 7, we see a more statistically significant liquidity effect at longer horizons using the revised nonborrowed reserves series. Moreover, the decrease in the federal funds rate from a positive nonborrowed reserves shock is persistent, without the sign changes seen from the old nonborrowed reserves series.

\section{Permutations of the Nonstructural VAR Approach to Identifying Monetary Policy Shocks}

We also considered four alternative nonstructural VAR specifications from the literature, such as Eichenbaum's (1992) reordering of the four-variable model: $(P, Y$, NBRD, FF). Sims (1992) al so suggested that sensitive commodities prices could capture information on future inflationary pressure beyond that embodied in the consumer price index. Christiano, Eichenbaum and Evans (1995) estimated orderings of VARs with commodities prices that corresponded with monetary targeting and interest-rate targeting. Strongin (1995)

${ }^{5}$ Ninety percent confidence intervals have become the norm for analyzing VAR output.
(NBRX) could represent monetary policy shocks. In each case, however, we found that it did not make a substantive difference whether we used the old series or the revised one in these VARs. One exception might be the Strongin (1995) model, where for the old measures, TR accounts for about 9 percent of the variance of output and NBRX for about 45 percent. With the revised series, these statistics become 16 percent and 37 percent, respectively, so there is some sensitivity to changes in the money measure. On the other hand, N BRX explains about 10 percent of the variance of $F F$ at the 5-year horizon, irrespective of whether the old or the new series is used.

\section{Bernanke and Mihov's Structural VAR and Changes in Operating Procedures}

In the nonstructural models discussed above, the VAR framework forces the analyst to decide for the entire sample period whether monetary policy was conducted through interest-rate targeting or monetary control. In contrast, the Bernanke and Mihov (1995) model of monetary policy shocks allows the monetary policy operating procedure to switch over time between interest-rate targeting and monetary control. In their structural VAR, Bernanke and Mihov identify a monetary policy shock that is a linear combination of the forecast errors of total reserves, nonborrowed reserves and the fed funds rate. Depending on the operating procedure, the monetary policy shock inferred from the model can be a function of one or more of these forecast errors. Given that the Fed changed its operating procedure temporarily and controlled growth in nonborrowed reserves from 1979 to 1982 (a period that falls in the middle of our sample), the Bernanke-Mihov allowance for changes in operating procedure seems appropriate. For space considerations, we do not discuss the quantitative derivation of the monetary policy shock in the Bernanke-Mihov model. Full details are available in Bernanke-Mihov (1995). 


\section{Figure 5}

\section{Impulse Responses, \{FF, MB, P, Y\} Model}

Monthly data: 1959:1-1995:6

Shock to OLDMB

\section{Response of FF}

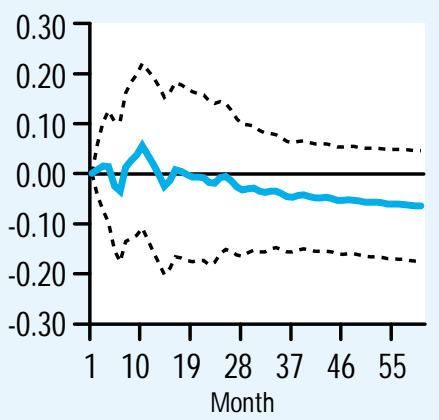

Response of OLDMB

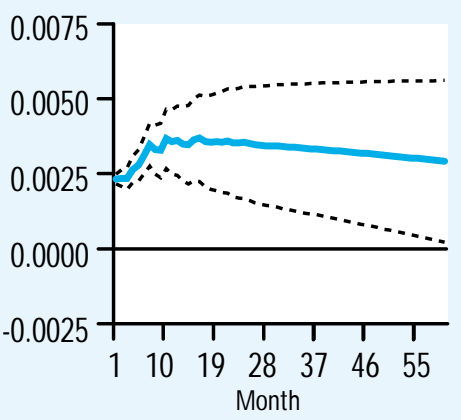

Response of $\mathbf{P}$

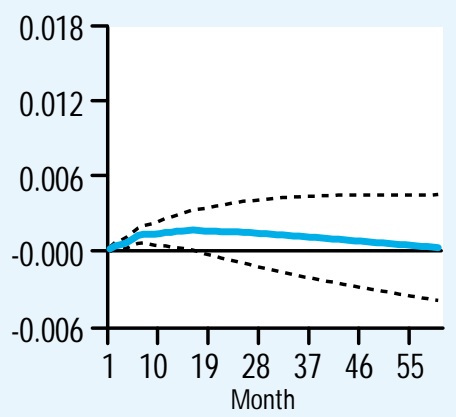

Response of $\mathbf{Y}$

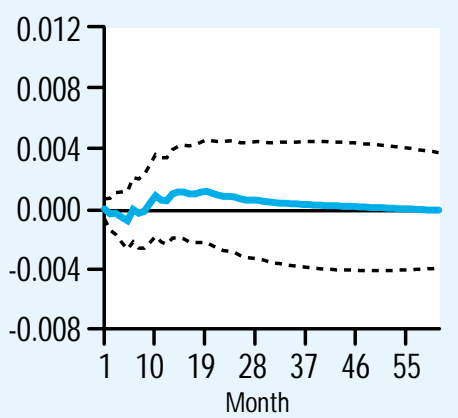

Shock to NEWMB

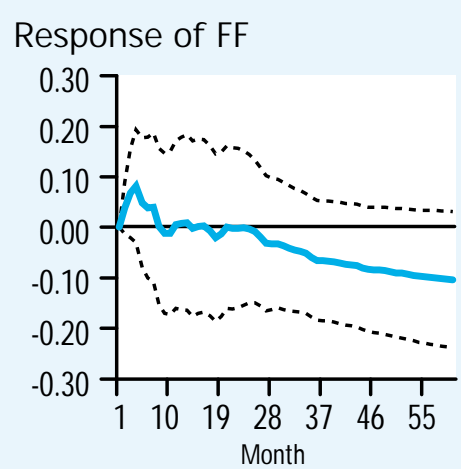

\section{Response of NEWMB}

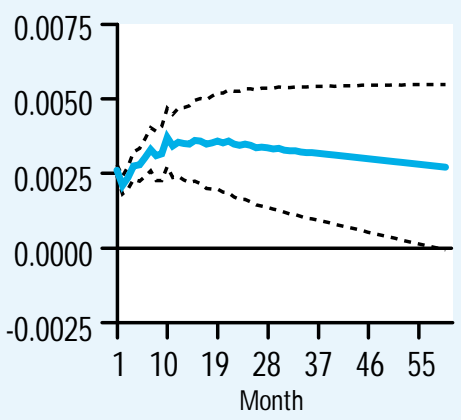

\section{Response of $\mathbf{P}$}

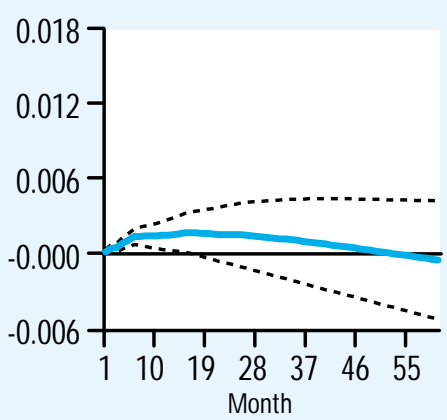

\section{Response of $Y$}

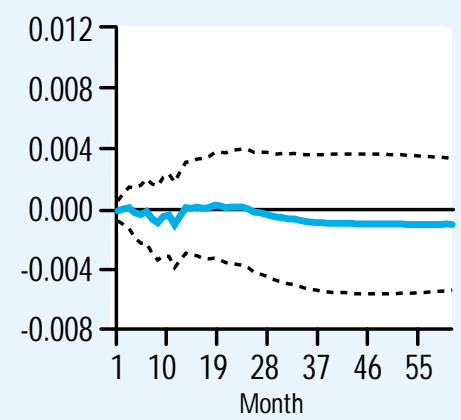




\section{Figure 6}

\section{Impulse Responses, \{FF, TR, P, Y\} Model}

Monthly data: 1959:1-1995:6

Shock to OLDTR

\section{Response of FF}

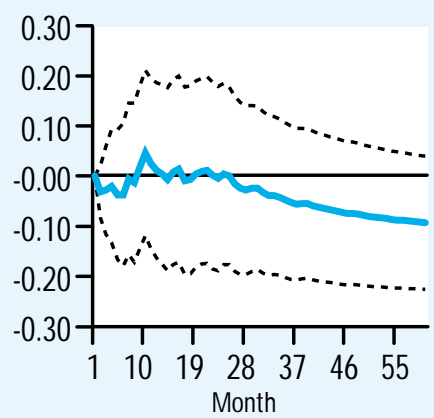

Response of OLDTR

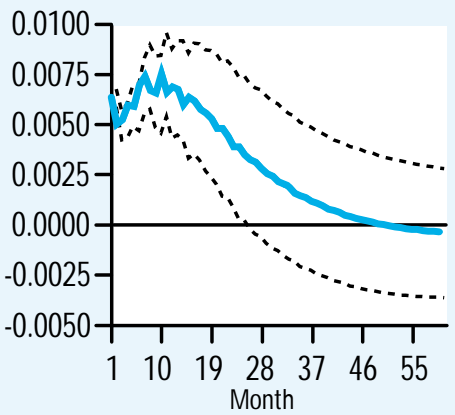

Response of $\mathbf{P}$

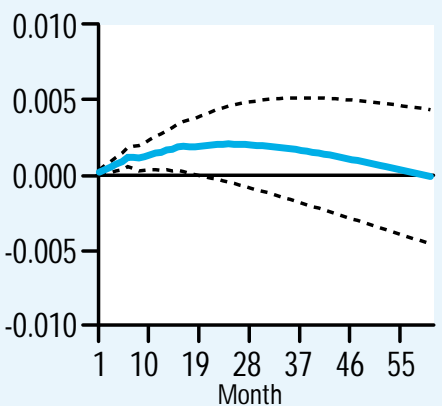

Response of $\mathbf{Y}$

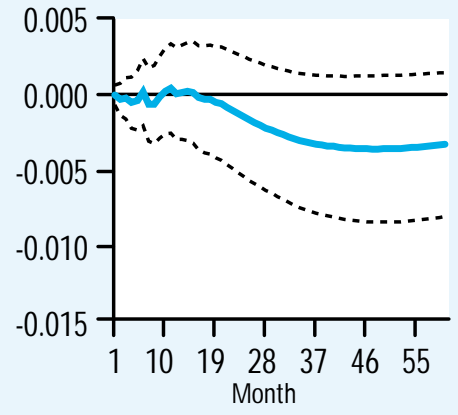

Shock to NEWTR

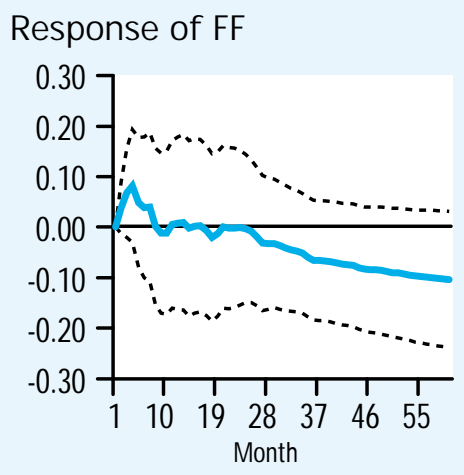

\section{Response of NEWTR}

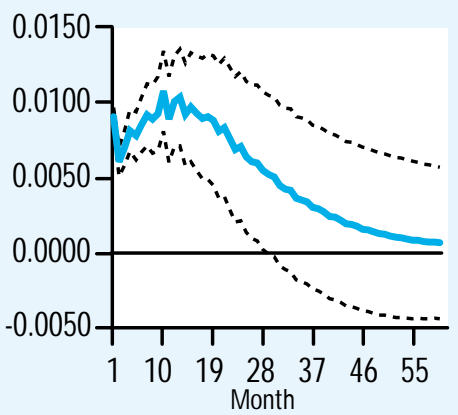

Response of $\mathbf{P}$

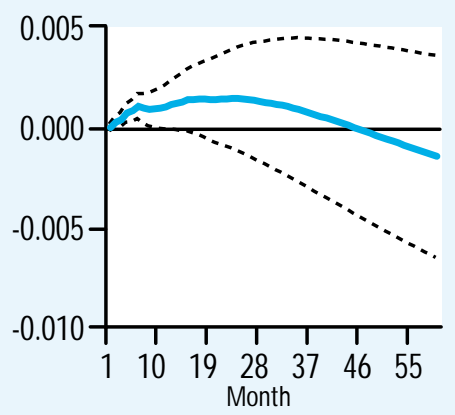

Response of $\mathbf{Y}$

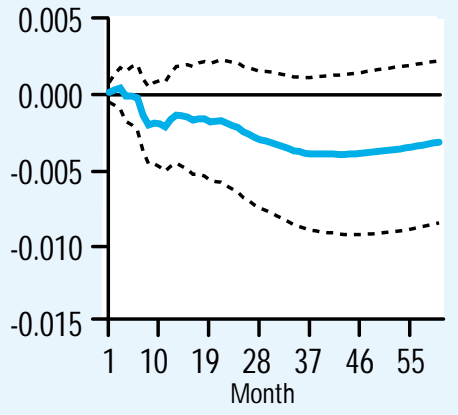




\section{Figure 7}

\section{Impulse Responses, \{FF, NBRD, P, Y\} Model}

Monthly data: 1959:1-1995:6

Shock to OLDNBRD

\section{Response of FF}

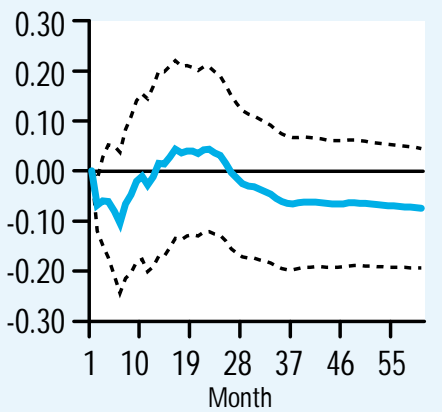

Response of OLDNBRD

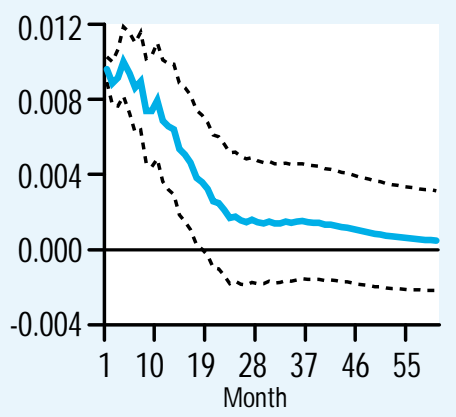

\section{Response of $\mathbf{P}$}

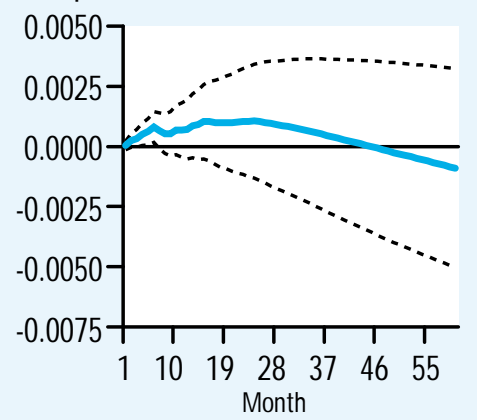

Response of $Y$

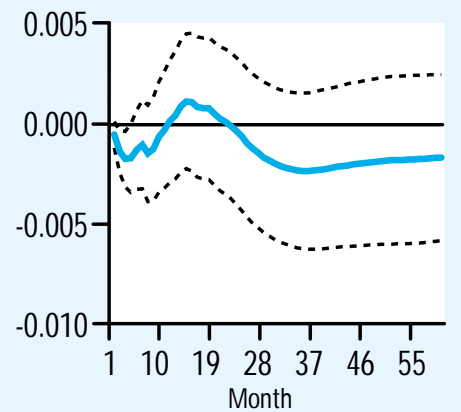

Shock to NEWNBRD

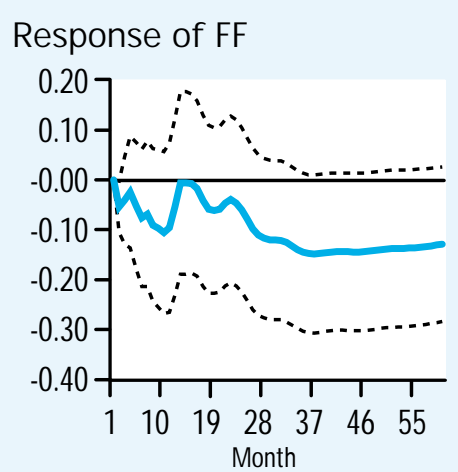

Response of NEWNBRD

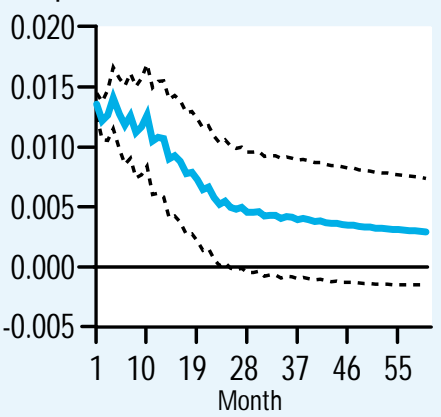

Response of $\mathbf{P}$

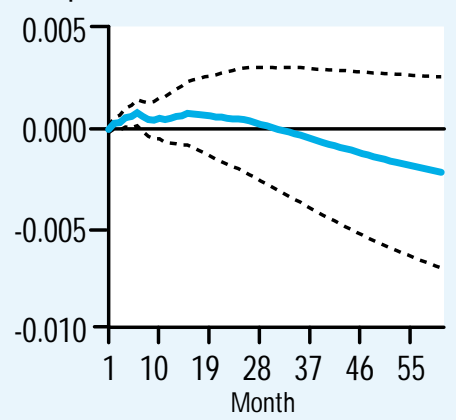

Response of $\mathbf{Y}$

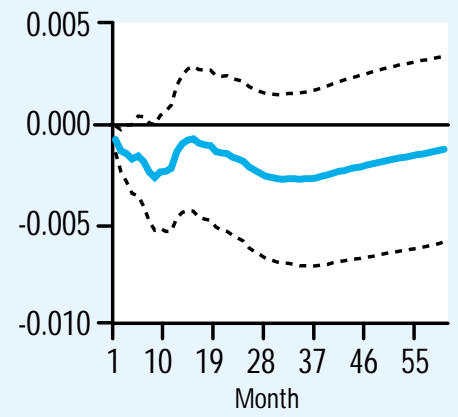




\section{Figure 8}

\section{Bernanke-Mihov Impulse Responses to a Monetary Policy Shock (Old Reserves Measure)}

Response of GDP

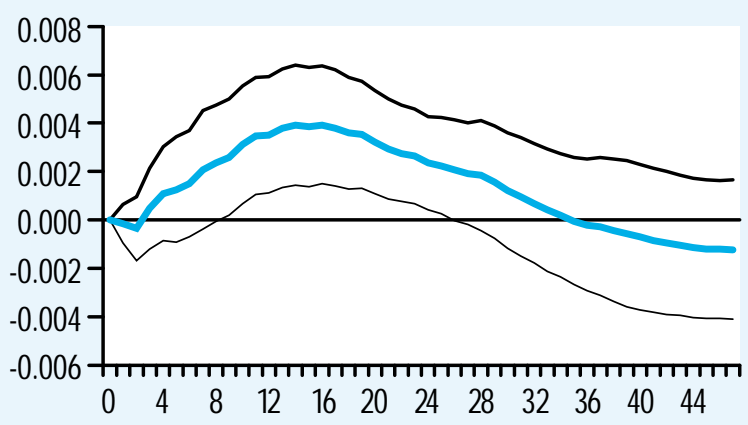

Response of PGDP

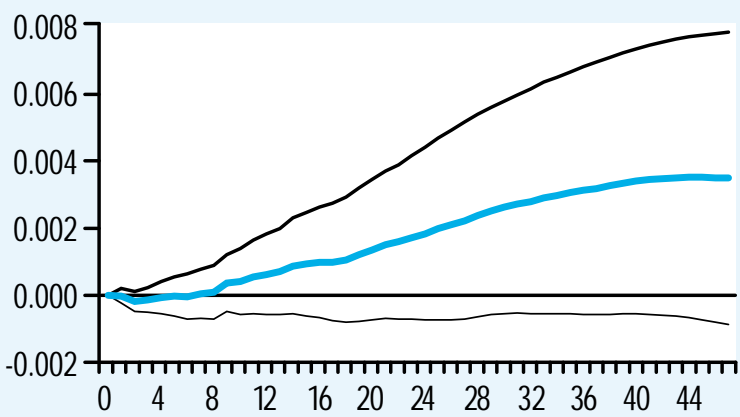

Response of PCOM

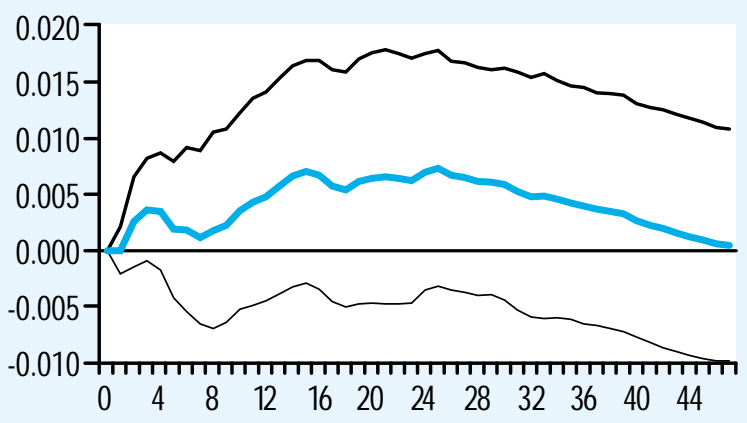

The model contains five variables (including commodities prices denoted PCOM) and is structural, so that the order of the variables is no longer key to identification. Following Bernanke and M ihov (1995), we present impulse response functions to a "typical" monetary policy shock. Figure 8 contains plots of the impulse
Response of TR

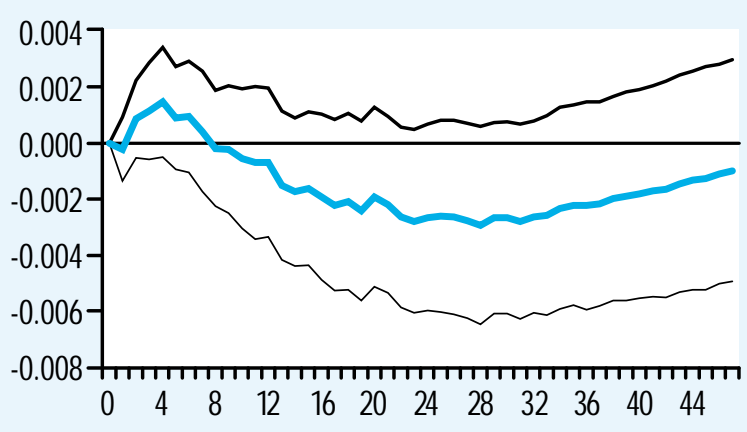

\section{Response of NBR}

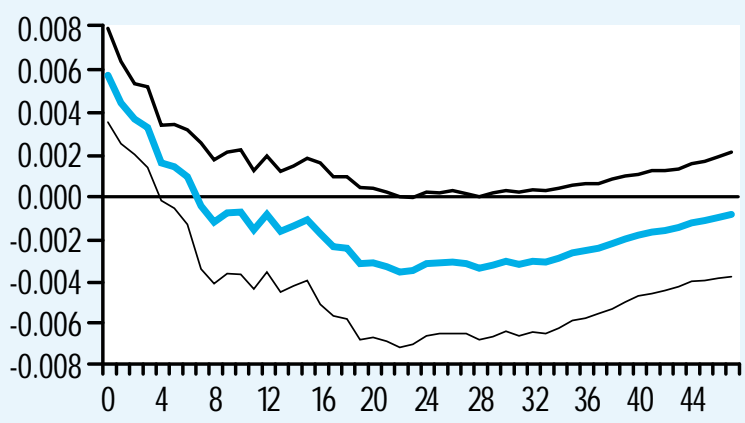

\section{Response of FFR}

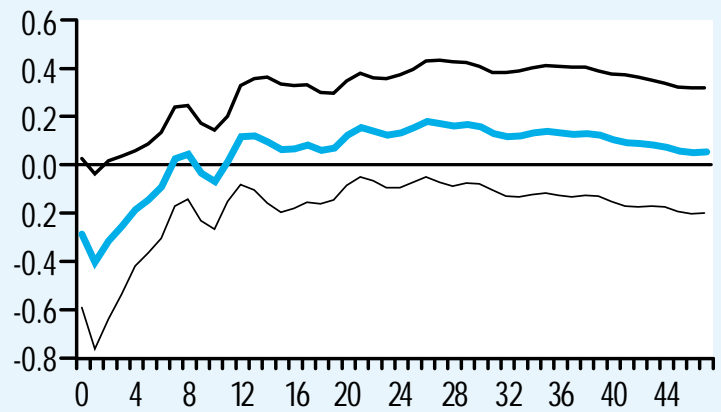

response functions using the old definitions of total reserves and nonborrowed reserves. Unlike some of the simpler VAR models (see Figure 5, for example), in this model the price level rises in response to a positive monetary policy shock, although the 90 percent confidence interval still contains zero. Output increases for about three years 


\section{Figure 9}

\section{Bernanke-Mihov Impulse Responses to a Monetary Policy Shock (New Reserves Measure)}

\section{Response of GDP}

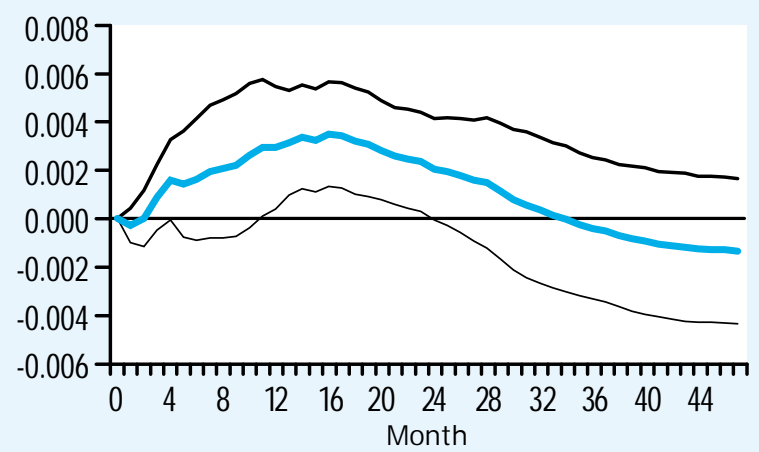

Response of PGDP

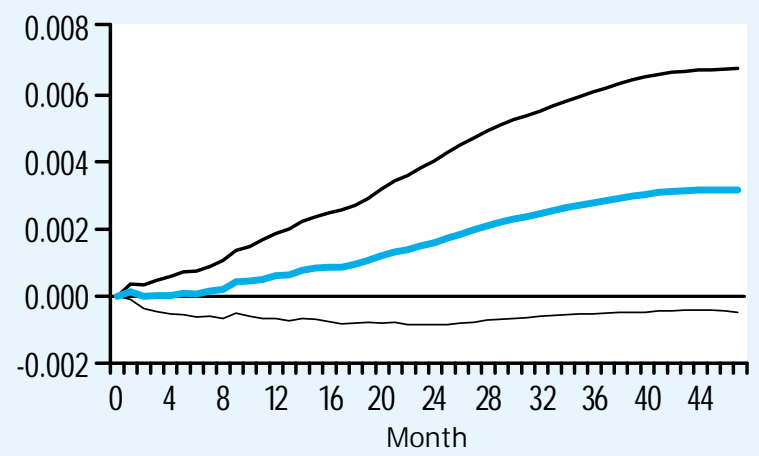

Response of PCOM

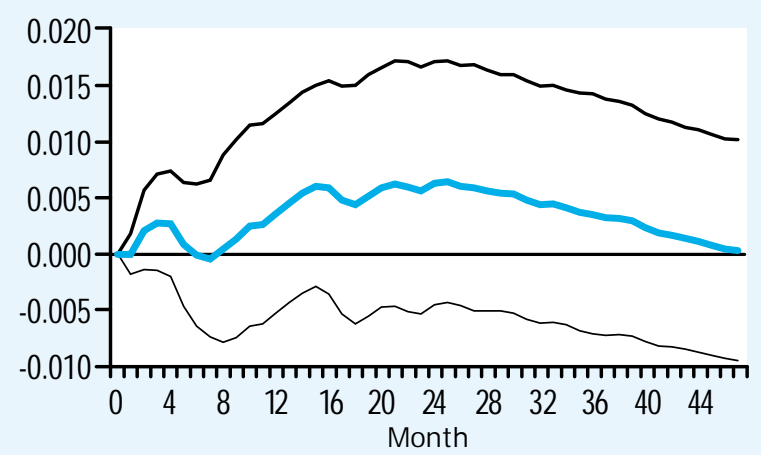

Response of TR

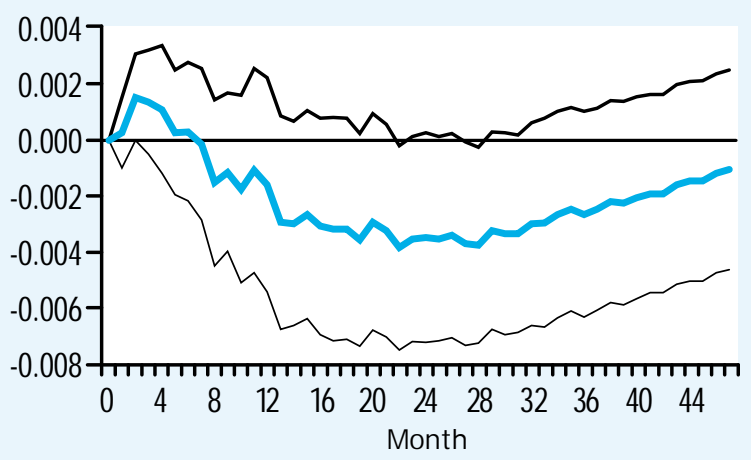

Response of NBR

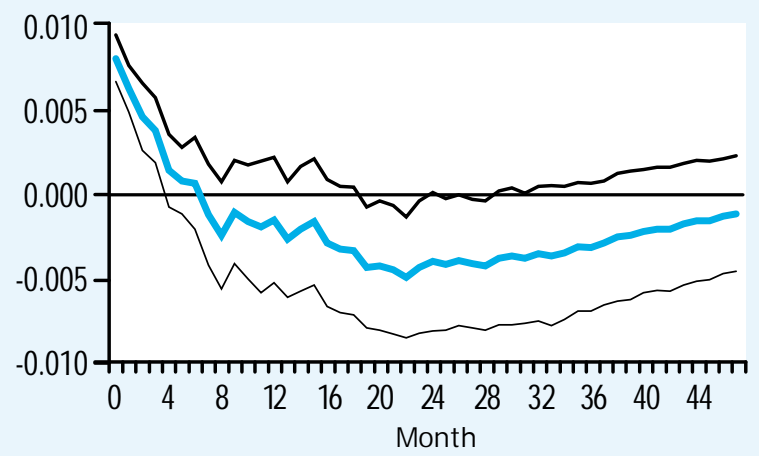

Response of FFR

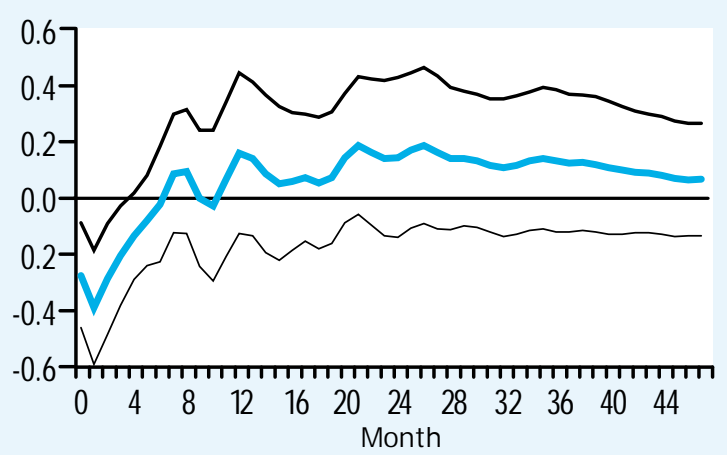

in response to a positive monetary policy shock and commodity prices respond weakly. Figure 9 has the corresponding charts for the revised measures of adjusted reserves. The most noteworthy difference between results for the old and revised series is that with the revised series, the 90 percent confidence interval for the response of the price level (denoted PGDP for GDP deflator) to an expansionary monetary policy shock is unambiguously positive at long horizons (after about 30 months). Otherwise, the response patterns for output and commodity prices are similar to those derived from the old measures of adjusted reserves. 


\section{Table 4}

\section{Structural Decomposition of VAR Residuals \\ (Revised and Old Definitions of Adjusted Monetary Base for 1980-95)}

\begin{tabular}{|c|c|c|}
\hline Coefficient & Revised data & Old data \\
\hline$\beta_{1}$ & .743 & .705 \\
\hline$\beta_{2}$ & .501 & .406 \\
\hline$\beta_{3}$ & .675 & 1.31 \\
\hline$\beta_{4}$ & -5.55 & -4.10 \\
\hline$\beta_{5}$ & 5.49 & 4.61 \\
\hline$\beta_{6}$ & -.061 & -.295 \\
\hline$\beta_{7}$ & -.163 & -.434 \\
\hline$\beta_{8}$ & .048 & -.206 \\
\hline$\beta_{9}$ & .933 & .145 \\
\hline$\beta_{10}$ & -1.42 & -1.89 \\
\hline$\sigma_{\mathrm{z} 1}$ & .569 & .602 \\
\hline$\sigma_{\mathrm{z} 2}$ & .413 & .463 \\
\hline$\sigma_{\mathrm{z} 3}$ & 3.78 & 3.00 \\
\hline$\sigma_{\mathrm{z} 4}$ & .219 & .248 \\
\hline$\sigma_{\mathrm{z} 5}$ & 1.12 & 1.28 \\
\hline
\end{tabular}

OPEN MARKET OPERATIONS AND RESERVE REQUIREMENT CHANGES AS MONETARY POLICY INDICATORS

\section{Haslag and Hein's Search for Differential Impacts}

An index of monetary policy actions such as the adjusted monetary base assumes that open-market purchases, which increase the supply of bank reserves, are economically equivalent to reserve-requirement reductions that "liberate" an equal amount of reserves by reducing the demand for reserves. Haslag and Hein (1995) have recently examined this assumption in their article, "Does it matter

${ }^{6}$ We estimate only their benchmark "monetarist" model and not their other "Keynesian" or "supply-shock" models. how monetary policy is implemented?" They look for differential impacts of reserve-requirement shocks and sourcebase shocks in the dynamic responses of output and inflation. For this reason, they use structural vector autoregressions to identify the shocks and study the impulse responses. We re-examine their structural VAR to see if the revised adjusted monetary base provides new and different evidence regarding this question. ${ }^{6}$ One piece of analysis that we add to Haslag and Hein is some judgment regarding the modelimplied variance decompositions.

Given that the adjusted monetary base equals the source base plus the reserve adjustment magnitude ( $A M B=H+R A M)$, $H$ aslag and Hein separate changes in the source base and changes in the reserve adjustment magnitude (RAM) that comprise the adjusted base into two stationary components:

$$
\begin{aligned}
& \hat{H_{t}}=\Delta H_{t} /\left[\left(A B_{t}+A M B_{t-1}\right) / 2\right] \text { and } \\
& \left.R \hat{A M} M_{t}=\Delta \text { RAM }_{t} /\left[\left(A^{2} B_{t}+A M B_{t-1}\right\}\right) / 2\right] .
\end{aligned}
$$

They include these two variables in a third-order VAR with the M 2 money multiplier (mm2), inflation and real GDP. The money multiplier is included because high-powered money might respond to changes in the multiplier. The VAR residuals (u) are decomposed into orthogonal "structural" residuals ( $z$ ) through a set of contemporaneous restrictions:

(5)

$$
\begin{aligned}
& u_{R A M}=z_{1}, \\
& u_{H}=\beta_{1} u_{R A M}+\beta_{2} u_{m m 2}+\beta_{3} u_{I N F}+z_{2}, \\
& u_{m m 2}=\beta_{4} u_{I N F}+\beta_{5} u_{G D P}+z_{3}, \\
& u_{I N F}=\beta_{6} u_{R A M}+\beta_{7} u_{H}+z_{4} \text {, and } \\
& u_{G D P}=\beta_{8} u_{R A M}+\beta_{9} u_{H}+\beta_{10} u_{m m 2}+z_{5} .
\end{aligned}
$$

Using quarterly data from 1980-95, we obtained parameter estimates ( shown in Table 4) for the just identified model, by applying both the revised and the old adjusted monetary bases to measure the source base and RAM. More important than the contemporaneous relations captured by the coefficients, however, are the impulse responses and variance decompositions, especially the way in which output and inflation respond to innovations in $\mathrm{H}$ and RAM. Figure 10 provides the impulse responses of output and inflation to reserve- 


\section{Figure 10}

\section{Responses of GDP and Inflation (post-1980) to RÂM and $\hat{H}$}

a. GDP New

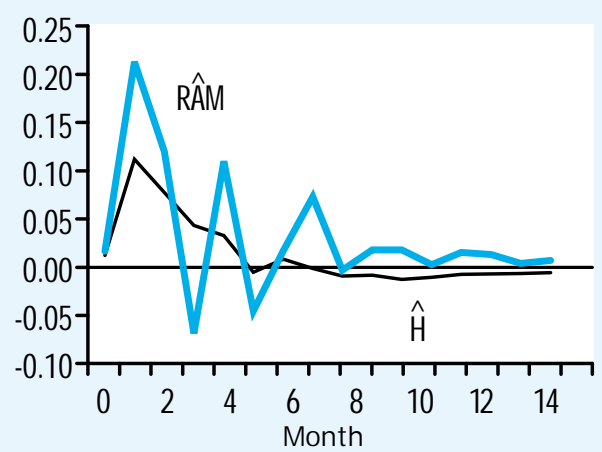

c. Inflation New

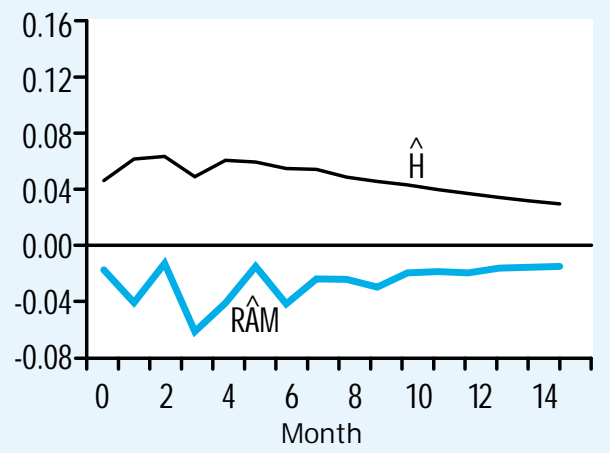

requirement and source-base shocks. Haslag and Hein (1995) look for evidence that the two monetary-policy innovations generate similar impulse responses. Figures $10 \mathrm{a}$ and $10 \mathrm{~b}$ report results for GDP responses, using the revised and old data definitions. In each case, output growth is higher for about four quarters before returning to zero or turning slightly negative. ${ }^{7}$ This finding is qualitatively very similar to that of Haslag and Hein. The estimated impulse response to a required reserves shock, however, is quite volatile and apparently imprecisely estimated, as one would expect, since reserve requirement changes are infrequent. Nevertheless, the results concur with those found by Haslag and Hein, using either the revised or old definitions of the monetary base, in that the output response paths are qualitatively similar for both source-base and required-

\section{b. GDP Old}

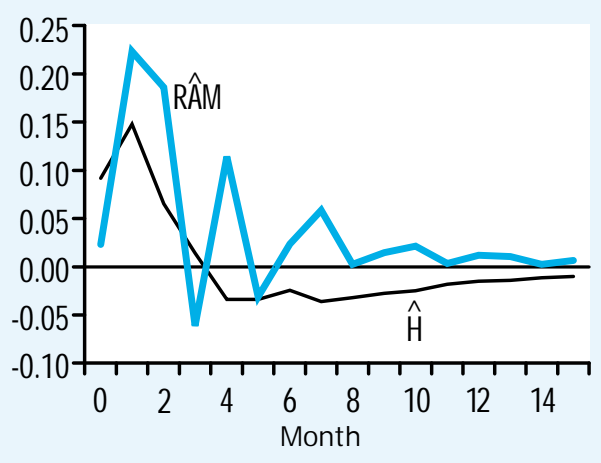

\section{d. Inflation Old}

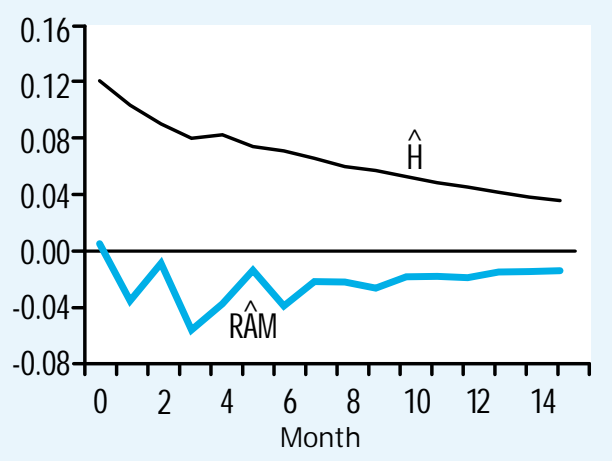

reserve shocks. With respect to inflation, the revised monetary base data suggest different impacts from source-base shocks and required-reserve shocks in Figure 10c. A positive shock to source-base growth has a persistently positive effect on inflation, whereas a required-reserve shock has a somewhat negative (and al most certainly insignificant) impact on inflation. The old monetary base data give a similar picture but find a much greater magnitude than the revised data for the response of inflation to a source-base shock in Figure 10d.

Haslag and Hein do not report variance decompositions, but they are important diagnostics for a structural model, because it helps to know how often these impulses are striking and how large they are. The first two rows of Table 5 contain the forecast variance decomposition for output for 16quarter forecasts. This decomposition is
Confidence intervals for the impulse responses were not derived since they required Monte Carlo simulations of re-estimations of the structural decompositions, which proved to be fragile in their convergence. 


\section{Table 5}

\section{Output and Inflation Variance Decompositions for 16-Quarter Forecast Errors (1980-95)}

Percent of Variance by Innovation Source (Rows Sum to 100)

\begin{tabular}{|c|c|c|c|c|c|}
\hline & RAM & Source base & M2 mult. & Inflation & GDP \\
\hline \multicolumn{6}{|l|}{ Output: } \\
\hline Revised Base & 12.6 & 3.3 & 62.6 & 10.7 & 10.9 \\
\hline Old Base & 15.3 & 6.0 & 54.5 & 10.1 & 14.1 \\
\hline \multicolumn{6}{|l|}{ Inflation: } \\
\hline Revised Base & 8.3 & 23.6 & 1.9 & 62.3 & 3.9 \\
\hline Old Base & 6.4 & 47.7 & 2.2 & 36.5 & 7.2 \\
\hline
\end{tabular}

representative for all horizons. We find no real distinction between the revised definition and the old definition of the adjusted monetary base regarding the roles played by source-base and required-reserve shocks in determining the variance of output. The decomposition of the inflation forecast error, given in the last two rows of Table 5, shows that the old definition gives a much larger role to source-base shocks. The revised definition, in contrast, attributes more of the variation in inflation to persistent, idiosyncratic shocks to inflation itself. Hence our main finding in using the revised definition versus the old one is that, according to the revised measure, inflation appears less driven by innovations in high-powered money growth than the old adjusted monetary base would suggest.

\section{The Impact of Reserve Requirement Changes on Output and Investment}

For empirical evidence that the amount of financial intermediation is an important determinant of output and investment, Loungani and Rush (1995) look to reserve requirement changes as exogenous shifts in the effective tax rate on intermediation. They note that other measures of intermediation are simultaneously determined with real output, whereas reserve requirement changes are generally made for technical reasons not associated with the business cycle. Their hypothesis is that decreases in reserve requirements lower the tax on intermediation and act as a positive shock to bank lending and real economic activity.

Loungani and Rush (1995) obtain a stationary measure of the magnitude of the reserve requirement changes by taking log differences of the ratio between the adjusted and unadjusted monetary base. They denote the log of this ratio as $F$ and its first difference as DF. The unadjusted base is the source base from the Fed's balance sheet, and the adjusted base adds a reserve adjustment magnitude (RAM) to couch the impact of reserve requirement changes in terms of an equival ent change in high-powered money. Loungani and Rush also use an alternative measure of DF based on the ratio of adjusted to unadjusted reserves to abstract from the large role that currency plays in the monetary base.

The basic empirical proposition of Loungani and Rush is that reserve requirement changes, summarized by DF, have significant explanatory power in reduced-form OLS regressions of output growth and investment growth. Our purpose is to run the Loungani and Rush regressions using both the revised (new) and old definitions of the adjusted monetary base and adjusted reserves to see if the conclusions regarding the potency of monetary policy change.

In their regressions, Loungani and Rush include other conditioning variables in addition to DF. They find little sensitivity to four alternative measures of monetary policy. We follow their use of the change in $\mathrm{M} 1$ growth as a conditioning variable. Twice differencing the log of $\mathrm{M} 1$ ensures that a change in the money growth rate does not permanently affect the output growth rate. They also condition on the real stock return, the change in the Standard and Poor's 500 index, as a measure of changes in real wealth. Lags of these conditioning variables are included in the regression, because it may take time for real economic activity to respond to shocks. We follow Loungani and Rush by using eight lags of each explanatory variable, but we do not use the contempora- 
neous (zero lag) values. One might argue that the explanatory variables are exogenous vis-a-vis today's output, but we chose to include only lagged values.

Denoting (in logs) output as $Y$, investment as I, and stock prices as $S$, and the differencing operator as $D$, the regression specification is

$$
\begin{aligned}
& D Y_{t}=\beta+\pi D Y_{t-1}+\sum_{k=1}^{8} \delta_{k} D F_{t-k}+ \\
& \sum_{k=1}^{8} \Theta_{k} D D M 1_{t-k}+\sum_{k=1}^{8} \lambda_{k} D S_{t-k}
\end{aligned}
$$

where $D F$ is either $\Delta \ln (A M B / M B)$ or $\Delta \mathrm{n}$ (ARES/RES). AM B is the adjusted monetary base, $M B$ is the unadjusted monetary base, ARES are adjusted reserves, and RES are unadjusted bank reserves. Another regression is run with investment spending as the dependent variable. As discussed above, each of the regressions is run twice, once using the revised (new) definition of the adjusted base and reserves, and once using the old definitions.

Loungani and Rush (1995) measure the potency of monetary shocks by looking at the statistical significance of the cumulative effect of a reserve-requirement change on output and investment. Thus a key hypothesis test is whether the sum of $\delta_{k}$ coefficients from Equation 6 is significant. Following Loungani and Rush, we report the sum of the coefficients on DF through both four and eight lags and the probability values for the hypothesis that the sums are zero in quarterly data from 1962 to 1995.

The first two columns of Table 6 contain results for the base measures of DF, with results for the old and revised (new) measures of the base side by side. The primary difference in results between the old and revised measures of the adjusted base is that reserve-requirement shocks do not have a significant effect on output at the 5 percent level when the old measure is used, but are significant at 2 percent to 3 percent when the revised measure is applied. The results for investment activity, on the other hand, do not appear
Table 6

\section{Effects of Adjusted Base and Adjusted Reserves

\begin{tabular}{|c|c|c|c|c|c|}
\hline & & \multicolumn{4}{|c|}{ Sum of coefficients and $p$-values } \\
\hline & & old AMB & revised AM B & old ARES & revised ARES \\
\hline \multirow[t]{7}{*}{ Output: } & DDM1 & $\begin{array}{r}-.498 \\
(.35)\end{array}$ & $\begin{array}{r}-.443 \\
(.39)\end{array}$ & $\begin{array}{l}.082 \\
(.26)\end{array}$ & $\begin{array}{r}-.029 \\
(.80)\end{array}$ \\
\hline & DS & 0.20 & .019 & 0.20 & .018 \\
\hline & & $(.025)$ & $(.036)$ & $(.027)$ & $(.045)$ \\
\hline & $\mathrm{DF}(4)$ & .405 & .559 & .055 & .127 \\
\hline & & $(.082)$ & $(.021)$ & $(.34)$ & $(.041)$ \\
\hline & $\mathrm{DF}(8)$ & .527 & .695 & .082 & .166 \\
\hline & & $(.088)$ & $(.032)$ & $(.26)$ & $(.035)$ \\
\hline \multirow[t]{7}{*}{ Investment: } & DDM1 & -1.22 & -.715 & .550 & .548 \\
\hline & & $(.52)$ & $(.78)$ & $(.34)$ & $(.34)$ \\
\hline & DS & .118 & .107 & .114 & .103 \\
\hline & & $(.007)$ & $(.013)$ & $(.008)$ & $(.018)$ \\
\hline & $\mathrm{DF}(4)$ & 2.84 & 3.15 & .600 & .749 \\
\hline & & $(.017)$ & $(.010)$ & $(.039)$ & $(.018)$ \\
\hline & $\mathrm{DF}(8)$ & $\begin{array}{r}4.53 \\
(.004)\end{array}$ & $\begin{array}{r}4.63 \\
(.005)\end{array}$ & $\begin{array}{r}.954 \\
(.010)\end{array}$ & $\begin{array}{r}1.16 \\
(.004)\end{array}$ \\
\hline
\end{tabular} Shocks on Output and Investment Growth}

sensitive to which measure of the adjusted monetary base is used.

The last two columns of Table 6 provide the same tests using changes in the ratio of adjusted to adjusted reserves as the measure of reserve-requirement changes. The significance of the effect of reserve-requirement shocks on output differs between the old definition and the revised one even more dramatically for reserves than for the base. For the old adjusted monetary base, the sum of coefficients on DF was significant at 10 percent, but is not even close for the old adjustedreserves measure. Meanwhile, the revised adjusted reserves measure is significant in the output equation. As with the corresponding monetary base measures, the old definition shows little difference in significance levels from the revised definition with respect to the investment regression. N evertheless, the fact that the impact is statistically significant with either measure reinforces and adds robustness to the Loungani-Rush finding that exogenous reserve-requirement shocks matter. 
Based on their finding that reserverequirement shocks affect investment more strongly than output, Loungani and Rush conclude their paper with a regression of investment on the ratio of bank credit to total credit. Their focus on the investment channel stems from their finding differential significance levels for reserve-requirement shocks between the investment and output regressions. Our findings suggest that the impact of reserve-requirement shocks might be significant to both measures of economic activity if one uses the revised measures of adjusted reserves and adjusted monetary base.

\section{CONCLUSIONS}

Our investigation has identified several empirical results and conclusions that are sensitive to the choice between the old and revised measures of the adjusted monetary base and reserves. Our estimates suggest that the forecast error variances for base velocity are smaller for the revised monetary base from approximately 1985 to the present, a finding that leads to different inferences regarding the target rate of nominal GDP growth. In the VARs, which are designed to measure the effects of monetary policy shocks, the qualitative results are not sensitive to the choice of base and reserves measures, although the variance decompositions differ somewhat. The structural VAR from Bernanke and Mihov (1995) has its chief discrepancy in the inflation variance decomposition, where the old measure gives relatively more weight to source-base shocks. Finally, because of their focus on reserve-requirement shocks, the "credit view" regressions of Loungani and Rush (1995) offer a good place to distinguish between the two base measures. The alternative base measures give different answers regarding the significance of reserve-requirement shocks on output. While reserve-requirement shocks are an important determinant of investment for both measures, only the revised base measure suggests that reserve-requirement shocks significantly influence output.

\section{REFEREN CES}

Anderson, Richard G., and Robert H. Rasche. "Measuring the Adjusted Monetary Base in an Era of Financial Change," this issue of the Review, pp. 3-37

Bernanke, Ben S., and Alan S. Blinder. "The Federal Funds Rate and the Channels of Monetary Transmission," The American Economic Review (September 1992), pp. 901-21

_. _ _ and llian Mihov. "Measuring Monetary Policy," NBER Working Paper (1995).

Christiano, Lawrence J., and Martin Eichenbaum. "Identification and the Liquidity Effect of Monetary Shocks," Business Cycles, Growth and the Political Economy, A. Cuikerman, L.Z. Hercowitz, and L. Leiderman, eds., MIT Press (1992), pp. 335-70. , and Charles Evans. "The Effects of Monetary Policy Shocks: Some Evidence from the Flow of Funds," Review of Economics and Statistics (February1996), pp. 16-34.

Doan, Thomas A. RATS User's Manual Version 4, Estima (1995).

Dueker, Michael. "Indicators of Monetary Policy: The View from Implicit Feedback Rules," this Review (September/ October 1993), pp. 23-40.

and Andreas M. Fischer. "Inflation Targeting in a Small Open Economy: Empirical Results for Switzerland." Journal of Monetary Economics (May 1996), pp. 89-103.

Eichenbaum, Martin. "Comments" on "Interpreting the Macroeconomic Time Series Facts: The Effects of Monetary Policy" by C. Sims, European Economic Review (June 1992), pp. 1001-11.

and Charles L. Evans. "Some Empirical Evidence on the Effects of Shocks to Monetary Policy on Exchange Rates," Quarterly Journal of Economics (November 1995), pp. 975-1009.

Haslag, Joseph H., and Scott E. Hein. "Does It Matter how Monetary Policy is Implemented? " Journal of Monetary Economics (April 1995), pp. 359-86.

Loungani, Prakash, and Mark Rush. "The Effect of Changes in Reserve Requirements on Investment and GNP," Joumal of Money, Credit and Banking (May 1995), pp. 511-26.

"The Case For Rules in the Conduct of Monetary Policy: A Concrete Example," Economic Review, Federal Reserve Bank of Richmond (September/ October 1987), pp. 10-18.

McCallum, Bennett T. "Robustness Properties of a Rule for Monetary Policy," Carnegie-Rochester Conference Series on Public Policy (1988), pp. 173-203.

and Monica Hargraves. "A Monetary Impulse Measure for Medium-Term Policy Analysis." IMF Staff Studies for the World Economic Outlook (1995), pp. 52-69.

Pagan, Adrian R., and John C. Robertson. "Resolving the Liquidity Effect," this Review (May/ June 1995), pp. 33-54.

Sims, Christopher A. "Macroeconomics and Reality," Econometrica (J une 1980), pp. 1-48. 


\section{REVIEW}

NOVEMBER/ DECEMBER 1996

"Interpreting the Macroeconomic Time Series Facts: The

Effects of Monetary Policy," European Economic Review (June 1992), pp. 975-1000.

Stock, J.H., and M.W. Watson. "Testing for Common Trends." Joumal of the American Statistical Association (December 1988), pp. 1097 107.

Strongin, Steven. "The Identification of Monetary Policy Disturbances: Explaining the Liquidity Puzzle," Journal of Monetary Economics (August 1995), pp. 463-97. 